\title{
Temperature dependent bacteriophages of a tropical bacterial pathogen
}

\author{
Jinyu Shan ${ }^{1}$, Sunee Korbsrisate ${ }^{2}$, Patoo Withatanung ${ }^{2}$, Natalie Lazar Adler ${ }^{1}$, Martha R. J. Clokie ${ }^{1{ }^{* t}}$ and \\ Edouard E. Galyov ${ }^{1+}$
}

1 Department of Infection, Immunity and Inflammation, University of Leicester, Leicester, UK

2 Department of Immunology, Faculty of Medicine, Siriraj Hospital, Mahidol University, Bangkok, Thailand

\section{Edited by:}

Eric Altermann, AgResearch Ltd., New Zealand

\section{Reviewed by:}

Eric Altermann, AgResearch Ltd., New Zealand

Olivia McAuliffe, Teagasc, Ireland

Catherine Maylin Loc-Carrillo,

University of Utah, USA

\section{*Correspondence:}

Martha R. J. Clokie, Department of Infection, Immunity and Inflammation, University of Leicester, Leicester LE1 9HN, UK

e-mail:mrjc1@le.ac.uk

${ }^{\dagger}$ Martha R. J. Clokie and Edouard E. Galyov are Co-senior authors.
There is an increasing awareness of the multiple ways that bacteriophages (phages) influence bacterial evolution, population dynamics, physiology, and pathogenicity. By studying a novel group of phages infecting a soil borne pathogen, we revealed a paradigm shifting observation that the phages switch their lifestyle according to temperature. We sampled soil from an endemic area of the serious tropical pathogen Burkholderia pseudomallei, and established that podoviruses infecting the pathogen are frequently present in soil, and many of them are naturally occurring variants of a common virus type. Experiments on one phage in the related model $B$. thailandensis demonstrated that temperature defines the outcome of phage-bacteria interactions. At higher temperatures $\left(37^{\circ} \mathrm{C}\right)$, the phage predominantly goes through a lytic cycle, but at lower temperatures $\left(25^{\circ} \mathrm{C}\right)$, the phage remains temperate. This is the first report of a naturally occurring phage that follows a lytic or temperate lifestyle according to temperature. These observations fundamentally alter the accepted views on the abundance, population biology and virulence of $B$. pseudomallei. Furthermore, when taken together with previous studies, our findings suggest that the phenomenon of temperature dependency in phages is widespread. Such phages are likely to have a profound effect on bacterial biology, and on our ability to culture and correctly enumerate viable bacteria.

Keywords: lysogeny, bacteriophages, Burkholderia pseudomallei, Burkholderia thailandensis, temperaturedependency

\section{INTRODUCTION}

It is increasingly accepted that bacterial physiology and evolution are impacted and often driven by phages (Abedon, 2008). Indeed, lytic phages that infect and kill their bacterial hosts shortly after infecting them, are key to shaping bacterial population dynamics by selectively eliminating particular strains of bacteria thus allowing others to dominate (Clokie et al., 2011). Alternatively, the genome of an infecting phage can become incorporated into the chromosome of its host bacterium, or exist as a plasmid (Prentki et al., 1977; Utter etal., 2014) without causing bacterial cell death. In this lysogenic life cycle, the phages can substantially influence bacterial phenotypes (Abedon and LeJeune, 2005). Studies of different phages and their bacterial hosts continue to reveal a remarkable interplay between bacteria and associated phages (Suttle, 2007; Zhao et al., 2013). These detailed interactions between phages and their host bacteria vary significantly, and have only been studied in detail for a few bacterial species of ecological, economic, or medical interest (Abedon, 2008). In this study, we set out to examine the environmental phages that infect the bacterial pathogen $B$. pseudomallei. Before this study, such phages had received little attention. B. pseudomallei is the causative agent of melioidosis, a severe and often fatal infection. (Wiersinga et al., 2012).

Although many phages have been isolated from soil, surprisingly little research has investigated the impact of phages on soil microorganisms, despite the ecological, agricultural, and environmental importance of the soil biome. Alongside other diverse organisms, the soil environment is inhabited by several bacterial species that are pathogenic to humans. Such pathogens normally subsist in the soil, but occasionally come into contact with humans and may cause disease (Berg et al., 2005; Baumgardner, 2012). The bacterium $B$. pseudomalle is one such pathogen that inhabits a tropical soil reservoir, where it may be found at densities of up to $10^{5}$ bacteria per gram of soil. Although $B$. pseudomallei can be found at various depths within the soil profile, the topsoil is considered to be the primary source of infection (Limmathurotsakul et al., 2010; Trung et al., 2011). This pathogen is endemic in many tropical areas; the highest number of cases of human infection is reported in South East Asia and Northern Australia (Limmathurotsakul et al., 2010; Trung et al., 2011).

Determining the factors that control bacterial dynamics in soils is of importance for understanding the disease melioidosis. Previous studies have identified that bacteria in the environment are controlled by physical factors, including temperature, salinity, $\mathrm{pH}$ and soil composition, in addition to biotic factors, such as vegetation type (Inglis et al., 2001; Inglis and Sagripanti, 2006; Limmathurotsakul et al., 2013). Little work has been carried out on the phages that infect this organism, and very few phages that are capable of propagating on B. pseudomallei have been identified. 
Numerous B. pseudomallei genomes have been sequenced in order to understand the biology of this pathogen. This has revealed the presence of several temperate phage genomes (Ronning et al., 2010; Kvitko etal., 2012). The aim of this work was to expand on our earlier study (Gatedee et al., 2011), and to focus on the phages that are found in the environment. To do this, we sampled soil from rice paddies from several locations in the North-Eastern part of Thailand where melioidosis is abundant. We isolated several phages that infect B. pseudomallei and the related bacteria, $B$. thailandensis. Four of the phage genomes were sequenced, and these are the first described genomes of podoviruses that infect this organism. We provide experimental evidence that the phages have a temperature dependent lifestyle, and that this factor has the potential to impact on the population dynamics and the pathogenicity of B. pseudomallei. The discovery of such phages has profound implications for our understanding of bacterial ecology.

\section{MATERIALS AND METHODS ISOLATION AND CHARACTERISATION OF PHAGES}

The phages analyzed in this study were isolated from soil samples in Thailand as previously described (Gatedee et al., 2011). In brief, the soil samples were suspended in SM buffer and vigorously mixed. The resulting supernatant was then used for the phage isolation enrichment procedure at $37^{\circ} \mathrm{C}$ employing $B$. pseudomallei K96243 as a host. From each sampling site, at least 10 samples were collected and assessed for the presence of the phages. Spot assays and plaque assays were then used to isolate the resulting phages, with the latter used to make the phages clonal (Limmathurotsakul et al., 2013).

Stocks of the phages were prepared and analyzed; their morphology was determined by transmission electron microscopy, which was carried out by Stefan Hyman from the Core Biotechnology Services at the University of Leicester. The methodology has been described previously (Shan etal., 2012).

Standard phenol chloroform extraction and isopropanol precipitation techniques were used for phage DNA extraction (Sambrook et al., 1989). Genome sequencing was performed by the Centre for Genomic Research, at the University of Liverpool, UK using Roche 454 technology. Annotation was carried out using Glimmer and GenemarkS to predict coding regions (Delcher et al., 1999; Besemer et al., 2001). The four complete genome sequences, ØВр-AMP1, ØВр-AMP2, ØВр-AMP3, and ØВр-AMP4, were deposited in the EMBL database under the Accession Numbers of HG793121, HG796219, HG796220, and HG796221, respectively. The major capsid proteins were identified bioinformatically using BLASTp searches in the NCBI database (Tamura et al., 2007; Kumar et al., 2008). The most similar sequences to phage $\varnothing B \mathrm{~B}-\mathrm{AMP} 1$ were then analyzed in MEGA (Molecular Evolutionary Genetics Analysis) version 5.2.2. Results from the neighbor joining analysis are presented, with a bootstrap analysis of 1,000 replicates. The phylogenetic trees were rooted with bacteriophage T7 as an outgroup. Maximum likelihood and parsimony analysis were also carried out. Phages were compared to each other at the nt level using the Artemis Comparison Tool (ACT; Carver et al., 2005).

\section{STUDIES OF BACTERIA-PHAGE INTERACTIONS}

To assess phage impact on bacterial growth at different temperatures, three biological replicates of $B$. thailandensis E264 cultures were grown at $37^{\circ} \mathrm{C}$ to mid-log phase and each was split into four aliquots. Two of each of the aliquots were then infected with ØBpAMP1, and two non-infected aliquots were used as a control. For each replicate, an infected and a non-infected control culture were incubated at $25^{\circ} \mathrm{C}$, and a second set at $37^{\circ} \mathrm{C}$ for $6 \mathrm{~h}$. The cultures were sampled hourly to estimate the bacterial density by measuring the $\mathrm{OD}_{600}$. The corresponding phage counts in the media were enumerated by counting the number of plaque forming units (PFU).

To determine how phage infection affects the ability of $B$. thailandensis to form colonies on a solid media, B. thailandensis E264 was grown to mid-log phase in liquid media and split into two aliquots. One aliquot was infected with ØBp-AMP1 at an MOI of 10 for $10 \mathrm{~min}$, and serially diluted samples were plated onto two sets of LB agar plates. One set was then incubated at $25^{\circ} \mathrm{C}$ and the other at $37^{\circ} \mathrm{C}$. Non-infected cultures were used as a control.

To assess stable lysogens, $B$. thailandensis E264 was infected with the phage, and the bacteria were plated on LB agar and incubated at $25^{\circ} \mathrm{C}$. A colony was determined to be phage positive using PCR. The bacteria were then propagated at $25^{\circ} \mathrm{C}$ and assessed in both in vitro and in vivo experiments. For the in vitro experiments, the lysogenic bacteria were grown in liquid medium at $25^{\circ} \mathrm{C}$ to midlog phase. For each of the two identical plates, $1 \mathrm{ml}$ of the culture medium (approximately $10^{6}$ bacteria) was mixed with $8 \mathrm{ml}$ of melted $0.4 \%(\mathrm{w} / \mathrm{v})$ agar precooled to $45^{\circ} \mathrm{C}$, and distributed evenly to solidify on the agar surface of a base plate. One of the resulting plates was then incubated over night at $25^{\circ} \mathrm{C}$, and the other at $37^{\circ} \mathrm{C}$. The phage binding efficiency at $25^{\circ} \mathrm{C}$ and $37^{\circ} \mathrm{C}$ was determined according to a previously published method (Jia et al., 2010). In order to test if phages can still inject DNA into the bacteria at $25^{\circ} \mathrm{C}$, ferrous ammonium sulphate (FAS) was used as a virucide to kill free phages, and phages inside the cell were tested using plaque assays (McNerney et al., 1998).

The two sets of PCR primers used in this study were designed using Primer-Blast. One targets the mazG gene ( $\mathrm{F}_{\text {mazG210 }}$ : CACACAGGCAGCAGTCAAGT; $\mathrm{R}_{\mathrm{mazG} 210}$ : GCGTACTTCCTCCGATACGA), the other one targets the phage $t$ t $B$ gene (Gatedee et al., 2011). Both primer sets are specific to the phages identified in this study. PCRs were carried out in a LabCycler (SensoQuest $\mathrm{GmbH}$, Göttingen, Germany) in total volumes of $50 \mu \mathrm{l}$, containing $0.25 \mathrm{mM}$ dNTPs, $3 \mathrm{mM} \mathrm{MgCl}, 2 \mu \mathrm{M}$ primers, $50 \mathrm{ng}$ of template DNA, 0.5 unit of Taq polymerase (Bioline, UK), and $5 \mu \mathrm{l}$ $10 \times$ Taq buffer (Bioline, UK). Amplification conditions were: $94^{\circ} \mathrm{C}$ for $2 \mathrm{~min}, 35 \mathrm{cycles}$ of $94^{\circ} \mathrm{C}$ for $45 \mathrm{~s}, 51^{\circ} \mathrm{C}$ for $45 \mathrm{~s}$, and $72^{\circ} \mathrm{C}$ for $1 \mathrm{~min}$, followed by a final extension of $10 \mathrm{~min}$ at $72^{\circ} \mathrm{C}$. PCR products were analyzed on a $1 \%(\mathrm{w} / \mathrm{v})$ agarose gel.

For the animal experiments, a phage positive colony maintained on $\mathrm{LB}$ agar at $25^{\circ} \mathrm{C}$ was suspended in physiological saline, and each of the five mice $(\mathrm{C} 57 \mathrm{Bl} / 6)$ were inoculated intravenously via the latteral tail vein with $\sim 10^{6}$ bacteria in $100 \mu \mathrm{l}$. The mice were sacrificed at $24 \mathrm{~h}$ post infection. The harvested spleen was homogenized in $2 \mathrm{ml}$ PBS in a Stomacher 80 Biomaster (Steward Ltd, UK) using 2 cycles of 30 s. $200 \mu$ l of the neat homogenate was 
spread plated, and the plates were incubated at $25^{\circ} \mathrm{C}$. The resulting colonies (15-20 for each sample) were assessed for the presence of the phage by PCR using the primers described above.

All investigations involving animals were carried out according to the requirements of the Animal (Scientific Procedures) Act 1986, including obtaining ethical approval from our local (University of Leicester) ethical review process. Mice were monitored for signs of disease during the experiment and humanely culled when predefined end-points were reached by cervical dislocation according to Schedule 1 of the Animal (Scientific Procedures) Act 1986.

\section{RESULTS}

\section{ISOLATION AND CHARACTERISATION OF PHAGES}

To study B. pseudomallei phages present in the environment, we sampled soil from rice paddies throughout North-Eastern Thailand and isolated numerous phages capable of infecting this bacterium (Figure 1A). Transmission electron microscopy revealed that most of the isolated viruses were podoviruses (Figure 1B). All of these podoviruses were morphologically similar to the phage that we previously described (Gatedee et al., 2011). Each of these phages could infect the B. pseudomallei K96243 strain and the related non-pathogenic $B$. thailandensis strain E264, although the efficiencies by which they infected the two species varied (data not shown).

Four of the podovirus genomes were selected to be sequenced on the basis of representing a wide geographical distribution as well as having differences in their plaquing efficiencies on the two bacterial species. The data revealed that the phages form a novel group of highly related viruses (Figures 1C,D). The genome architectures are conserved as shown in Figure 1C. When the genomes were compared using the ACT, they were found to be almost identical and only varied by three single nucleotide polymorphisms (SNPs) and three short insertions/deletions (Indels; Figure 1C). All SNPs and one Indel are located in the hypothetical proteins between the predicted integrase ORF and the DNA replication/repair module (Figure 1C). The second Indel is found within the DNA replication/repair module, specifically, it was in a hypothetical protein located between a DNA polymerase and an exonuclease. The final Indel was found within an ORF coding for a putative transglycosylase. Among the three SNPs, two would translate as a non-synonymous mutation and one a synonymous mutation in the resulting amino acid.

The phages encoded a tyrosine recombinase/integrase, which suggests that they can access the lysogenic lifestyle. Phylogenetic analysis was carried out on the capsid genes using neighbor joining and Maximum Likelihood analysis. Both analyses gave very similar tree topology and the results from the neighbor joining are presented. Despite this observation and the apparent abundance of these phages in the environment, no publicly available genomes of $B$. pseudomallei or B. thailandensis carry such phages (of the genomes of $46 \mathrm{~B}$. pseudomallei strains and 6 B. thailandensis strains, present in NCBI, August 2014).

\section{STUDIES OF BACTERIA-PHAGE INTERACTIONS}

To interpret why this phage group was not previously observed, we assessed phage-host interactions under different experimental conditions using $B$. thailandensis, a recognized model organism for B. pseudomallei (Haraga et al., 2008). The studies reported here focus on the impact of temperature on these interactions as this is a known variable affecting the bacterium in the environment. B. pseudomallei encounters different temperatures in the soil environment due to daily and seasonal variations, and it is also encounters the more consistent higher temperature when infecting warm-blooded hosts. To determine if the infection parameters of podoviruses differed with temperature, we conducted a detailed set of phage-bacterium interaction studies at $25^{\circ} \mathrm{C}$ and $37^{\circ} \mathrm{C}$. These temperatures are representative of the colder and warmer end of the temperature range at which the phage may encounter B. pseudomalle $i$ in the natural environment. Furthermore, $37^{\circ} \mathrm{C}$ has been shown to be the optimal temperature for propagation of the majority of B. pseudomallei strains under laboratory conditions (Chen et al., 2003).

To probe the impact of temperature on phage-host dynamics, liquid bacterial cultures were infected with phage ØBp-AMP1 (Gatedee et al., 2011) and incubated at either $25^{\circ} \mathrm{C}$ or $37^{\circ} \mathrm{C}$ with non-infected cultures used as a control. At $37^{\circ} \mathrm{C}$, the phage caused rapid bacterial lysis, whereas when incubated at $25^{\circ} \mathrm{C}$, both the phage-infected and non-infected bacteria grew steadily (Figures 2A,B). Adsorption assays showed that there were no difference in terms of binding efficiency as $\sim 90 \%$ of all of the phages bound to bacterial cells within $45 \mathrm{~min}$ at both a temperature of $25^{\circ} \mathrm{C}$ and at $37^{\circ} \mathrm{C}$. Furthermore, experiments using the virucide FAS confirmed that the phage can still inject DNA into host cells at both temperatures. This suggests that the phage infection cycle is temperature dependent, with a higher temperature permissive for lytic infection and the lower temperature for lysogenic infection.

To further assess the impact of temperature on the outcome of phage infection, plate assays were utilized. To do this, B. thailandensis cultures were infected with $\varnothing \mathrm{Bp}-\mathrm{AMP} 1$ in liquid media for $10 \mathrm{~min}$ at $37^{\circ} \mathrm{C}$, and serially diluted samples were plated and incubated at 25 or $37^{\circ} \mathrm{C}$. The phage-infected and control samples that were incubated at $25^{\circ} \mathrm{C}$, and the non-infected control incubated at $37^{\circ} \mathrm{C}$, yielded essentially the same number of colonies (Figure 2C). In contrast, the phage-infected sample incubated at $37^{\circ} \mathrm{C}$ yielded $\sim 2$ logs fewer colonies, this difference is statistically significant with a P-value of $<0.01$ (Figure 2C). Furthermore, of the 50 selected colonies that originated from the infected sample that grew at $25^{\circ} \mathrm{C}, 40$ were positive for phage presence as assessed by PCR with phage specific primers.

The stability of these lysogens was then characterized both in vitro and in vivo. In both cases the lysogen colonies were subcultured three times at $25^{\circ} \mathrm{C}$, and confirmed as phage positive using PCR. When these lysogens were grown in liquid media, ØBpAMP1 was detected in the culture supernatant at $37^{\circ} \mathrm{C}$ but not at $25^{\circ} \mathrm{C}$. Furthermore, when a lysogenic bacterial stock was embedded in $0.4 \%(\mathrm{w} / \mathrm{v})$ agar and incubated at $25^{\circ} \mathrm{C}$, confluent bacterial growth resulted. However, at $37^{\circ} \mathrm{C}$, only a patchy bacterial growth was observed, which is indicative of the lysogens being induced into the lytic cycle (Figure 2D).

Finally, to investigate the lysogen behavior in vivo, B. thailandensis bacteria from a PCR positive colony were suspended in physiological saline, and five mice $(\mathrm{C} 57 \mathrm{Bl} / 6)$ were inoculated intravenously with $\sim 10^{6}$ bacteria. B. thailandensis is a good model 


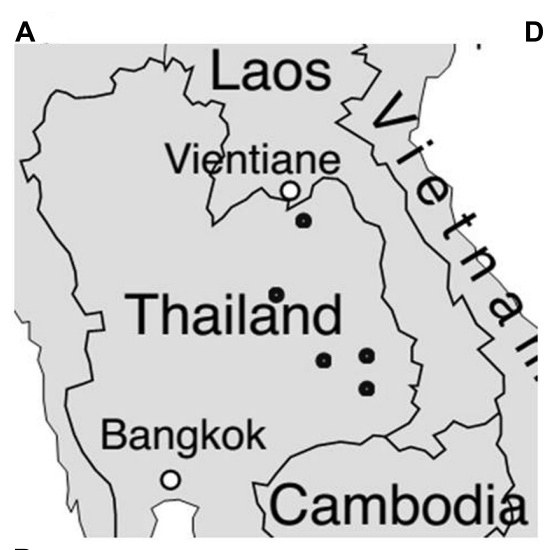

B

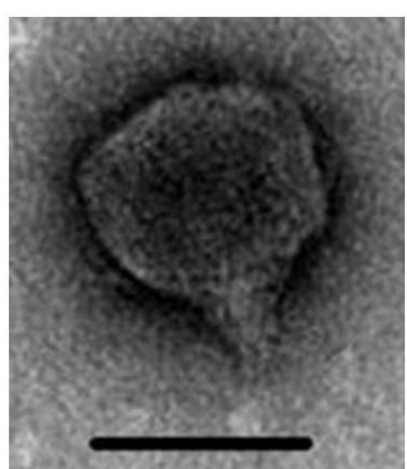

C

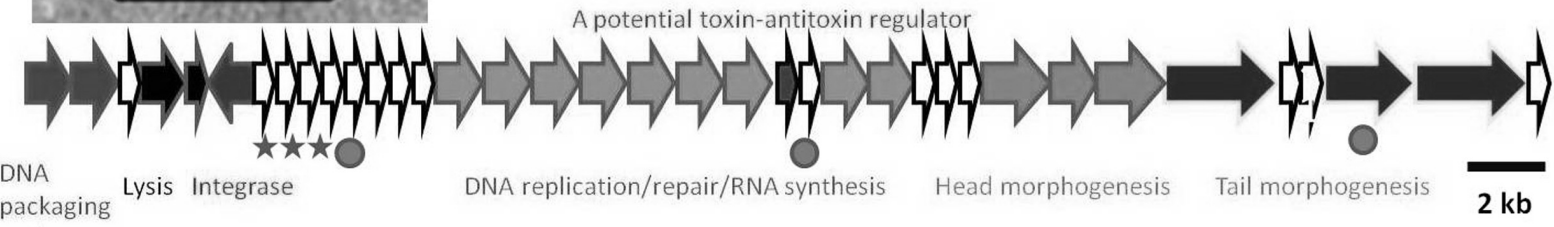

FIGURE 1 | Novel B. pseudomallei and B. thailandensis podoviruses are abundant in the pathogen endemic area of Thailand.

(A) Numerous phages were isolated from soil samples ( sampling locations are highlighted by dots). (B) TEM of a podovirus, typical of phages isolated in this study. Scale bar is $50 \mathrm{~nm}$. (C) Whole genome sequencing of four phages revealed an almost identical genome arrangements and content as illustrated here for ØBp-AMP1, the SNPs are shown with stars and the Indels with circles. Genomes have been deposited in EMBL. (D) Phylogenetic analysis based on the capsid protein for the four fully sequenced phages showing that the phages are novel and closely related to phages. Scale bar represents 0.2 amino acid changes per site. for B. pseudomallei because the two bacterial species are genetically closely related, and although $B$. thailandensis is not capable of causing disease in humans, it can cause disease signs in mice (Deshazer, 2007; Haraga et al., 2008). The mice were sacrificed at $24 \mathrm{~h}$ post infection, and homogenized spleen samples were plated and incubated at $25^{\circ} \mathrm{C}$. The resulting colonies (15-20 for each sample) were assessed for phage presence using PCR. No positive colonies were detected from samples from 4 of the mice, and only 3 of 20 colonies were phage-positive in the fifth sample. This demonstrated an in vivo selection against bacteria containing phages. It seems likely that only bacteria that lose their phage are capable of maintaining infection in a warm blooded animal.

\section{DISCUSSION}

Before our previous work (Gatedee et al., 2011) and this report, the only phages known to infect $B$. pseudomalle $i$ were all myoviruses (Yordpratum etal., 2011). In contrast, we isolated numerous podoviruses and demonstrated that they are common in tropical soil where they infect $B$. pseudomallei and B. thailandensis. We have shown that many of the phages are variants of a commonly occurring podovirus, and that they have a temperature dependent lifecycle at two contrasting environmentally relevant temperatures. It is highly plausible that these phages therefore have a profound and hitherto unrecognized effect on the population dynamics of bacteria. There are daily and seasonal periodic variations in temperature from $20^{\circ} \mathrm{C}$ to $37^{\circ} \mathrm{C}$ and above in the top-soil temperature in wet rice fields, a natural habitat for $B$. pseudomallei. It has been suggested that the optimal temperature for growth of the pathogen is $37-42^{\circ} \mathrm{C}$; by implication at such temperatures the highest numbers of bacteria will be present. It is therefore likely that the phage studied in our work has evolved to switch from a lysogenic to a lytic life style when the host bacteria are abundant. The induction of the phage during the bacterial infection of warm-blooded hosts may be caused as a result of temperature shift and the stress experienced by the bacteria as they enter this environment. 


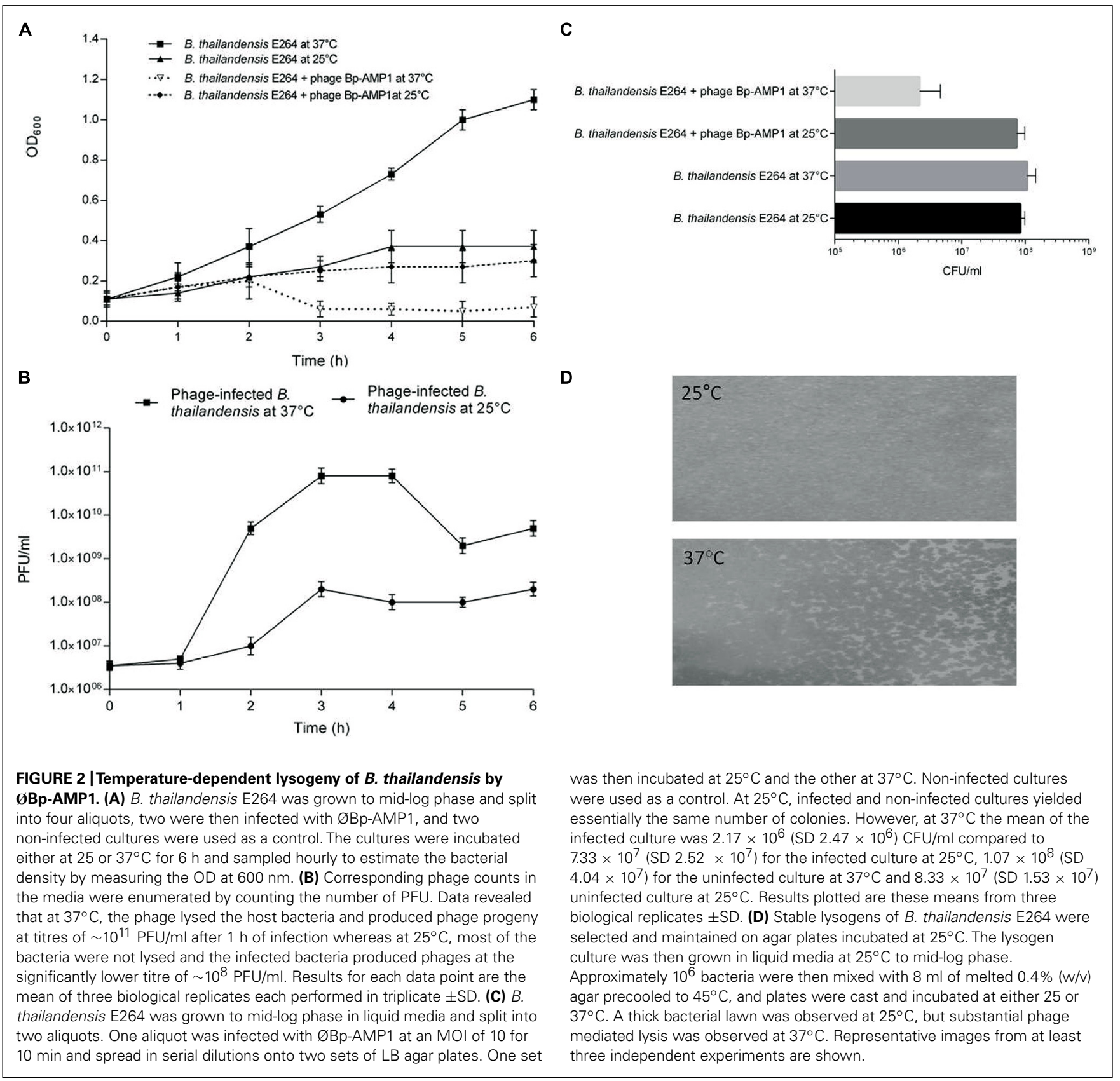

The observation that temperature can influence the outcome of phage-bacterial interactions has previously been made for other bacteria-phage systems. For example, temperature dependent restriction modification systems in industrially important lactobacilli are only active at lower temperatures, rendering bacteria less sensitive to phage infection (Sanders and Klaenhammer, 1984; O'Driscoll et al., 2004), and more lysogens seem to be present at low temperatures in aquatic cyanobacteria than there are at higher temperatures (McDaniel et al., 2006; Chu et al., 2011). Also of relevance to this work are studies on temperature sensitive mutant derivatives of lambda phage, which have also shown that a temperature shift causes such phages to be induced into the lytic cycle (Groman and Suzuki, 1962; Eshima et al., 1972; Lieb, 1979). To

the best of our knowledge, our observation is the first time that a clear shift for naturally occurring phages to enter a lysogenic or a lytic lifestyle depending on the temperature at which they coincide with their hosts has been demonstrated. Our work builds on previous descriptions of the importance of temperature to hostphage dynamics (Groman and Suzuki, 1962; Eshima et al., 1972; Lieb, 1979; Suzuki et al., 2002; McDaniel et al., 2006; Chu et al., 2011) and suggests that temperature dependent phage infections are widespread in nature. Thus, the scale and impact of the phenomenon of temperature dependent phages is likely to be very significant.

The findings presented here have several major implications for B. pseudomallei. The first relates to the environmental monitoring 
of the pathogen in which most methods of bacterial enumeration rely on selective growing of these bacteria at $37-42^{\circ} \mathrm{C}$ (Limmathurotsakul et al., 2013). Our data suggest that lysogens present in the natural bacterial population are unlikely to survive this isolation process due to phage activation; thus, there could be a major underestimation of bacterial numbers. This underestimation may also be further compounded by these phages, which once induced and released from their host bacteria, could subsequently infect any phage-free bacteria within the samples. Thus, the impact of these phages could cause a significant underreporting of the estimate of B. pseudomallei in the environment.

Our experiments also imply that phage-free bacteria are relatively more infective to human hosts than lysogens are. This is due to these temperate phages undergoing induction into the lytic cycle upon entry into a warm-blooded host. Therefore the relative infectivity of the inoculum if lysogens are present would be significantly lowered. This also would explain the observation that only the bacteria that are free from these podoviruses have been isolated and cultured from clinical samples.

The ability for this group of phages to lyse their host cells at higher temperatures is consistent with the apparent absence of lysogens in the strain collections, and also explains the lack of such phages in B. pseudomallei/B. thailandensis genome sequences. Thus, despite a substantial genome sequencing effort, this key aspect of bacterial diversity has not been revealed. The phenomenon of temperature dependent lysogeny could be an important element of the biology and pathogenesis for many other bacterial species, including other pathogens that can inhabit an environmental reservoir. Indeed the 'great plate count anomaly' (Staley and Konopka, 1985), that states that we can currently only culture $0.5-1 \%$ of all bacteria found in the natural world, could at least in part be explained by the impact of conditionally dependent phages.

\section{ACKNOWLEDGMENTS}

We thank Dr. Kanyanan Kritsiriwuthinan, Dr. Jiraporn Gatedee and students from the Department of Medical Technology, Rangsit University, Thailand for their assistance with soil sample collection. This work was supported by the Wellcome Trust, UK (Grant number 092638/Z/10/Z).

\section{REFERENCES}

Abedon, S. T. (2008). "Phages, Ecology, Evolution," in Bacteriophage Ecology, ed. S. T. Abedon (Cambridge: Cambridge University Press), 1-28.

Abedon, S. T., and LeJeune, J. T. (2005). Why bacteriophage encode exotoxins and other virulence actors. Evol. Bioinform. 1, 97-110.

Baumgardner, D. J. (2012). Soil-related bacterial and fungal infections. J. Am. Board Fam. Med. 25, 734-744. doi: 10.3122/jabfm.2012.05.110226

Berg, G., Eberl, L., and Hartmann, A. (2005). The rhizosphere as a reservoir for opportunistic human pathogenic bacteria. Environ. Microbiol. 7, 1673-1685. doi: 10.1111/j.1462-2920.2005.00891.x

Besemer, J., Lomsadze, A., and Borodovsky, M. (2001). GeneMarkS: a self-training method for prediction of gene starts in microbial genomes. Implications for finding sequence motifs in regulatory regions. Nucleic Acids Res. 29, 2607-2618. doi: $10.1093 /$ nar/29.12.2607

Carver, T. J., Rutherford, K. M., Berriman, M., Rajandream, M. A., Barrell, B. G., and Parkhill, J. (2005). ACT: the Artemis comparison tool. Bioinformatics 21, 3422-3423. doi: 10.1093/bioinformatics/bti553

Chen, Y. S., Chen, S. C., Kao, C. M., and Chen, Y. L. (2003). Effects of soil pH, temperature and water content on the growth of Burkholderia pseudomallei. Folia Microbiol. 48, 253-256. doi: 10.1007/BF02930965
Chu, T. C., Murray, S. R., Hsu, S. F., Vega, Q., and Lee, L. H. (2011). Temperatureinduced activation of freshwater Cyanophage AS-1 prophage. Acta Histochem. 113, 294-299. doi: 10.1016/j.acthis.2009.11.003

Clokie, M. R. J., Millard, A. D., Letarov, A. V., and Heaphy, S. (2011). Phages in nature. Bacteriophage 1, 31-45. doi: 10.4161/bact.1.1.14942

Delcher, A. L., Harmon, D., Kasif, S., White, O., and Salzberg, S. L. (1999). Improved microbial gene identification with GLIMMER. Nucleic Acids Res. 27, 4636-4641. doi: $10.1093 /$ nar/27.23.4636

Deshazer, D. (2007). Virulence of clinical and environmental isolates of Burkholderia oklahomensis and Burkholderia thailandensis in hamsters and mice. FEMS Microbiol. Lett. 277, 64-69. doi: 10.1111/j.1574-6968.2007.00946.x

Eshima, N., Fujiii, S., Murotsu, T., and Horiuchi, T. (1972). Lambda phage mutants insensitive to temperature-sensitive repressor. Mol. Gen. Genet. 116, 84-87. doi: 10.1007/BF00334262

Gatedee, J., Kritsiriwuthinan, K., Galyov, E. E., Shan, J. Y., Dubinina, E., Intarak, N., et al. (2011). Isolation and characterization of a novel podovirus which infects Burkholderia pseudomallei. Virol. J. 8, 366. doi: 10.1186/1743-422X-8-366

Groman, N. B., and Suzuki, G. (1962). Temperature and lambda phage reproduction. J. Bacteriol. 84, 431-437.

Haraga, A., West, T. E., Brittnacher, M. J., Skerrett, S. J., and Miller, S. I. (2008). Burkholderia thailandensis as a model system for the study of the virulenceassociated type III secretion system of Burkholderia pseudomallei. Infect. Immun. 76, 5402-5411. doi: 10.1128/IAI.00626-08

Inglis, T. J. J., Mee, B. J., and Chang, B. J. (2001). The environmental microbiology of melioidosis. Rev. Med. Microbiol. 12, 13-20. doi: 10.1097/00013542-20010100000002

Inglis, T. J. J., and Sagripanti, J. L. (2006). Environmental factors that affect the survival and persistence of Burkholderia pseudomallei. Appl. Environ. Microbiol. 72, 6865-6875. doi: 10.1128/AEM.01036-06

Jia, Y., Shan, J. Y., Millard, A., Clokie, M. R. J., and Mann, N. H. (2010). Light-dependent adsorption of photosynthetic cyanophages to Synechococcus sp. WH7803. FEMS Microbiol. Lett. 310, 120-126. doi: 10.1111/j.15746968.2010.02054.x

Kumar, S., Nei, M., Dudley, J., and Tamura, K. (2008). MEGA: a biologistcentric software for evolutionary analysis of DNA and protein sequences. Brief. Bioinform. 9, 299-306. doi: 10.1093/bib/bbn017

Kvitko, B. H., Cox, C. R., Deshazer, D., Johnson, S. L., Voorhees, K. J., and Schweizer, H. P. (2012). phi X216, a P2-like bacteriophage with broad Burkholderia pseudomallei and B. mallei strain infectivity. BMC Microbiol. 12:289. doi: 10.1186/1471-2180-12-289

Lieb, M. (1979). Heat-sensitive lambda repressors retain partial activity during bacteriophage induction. J. Virol. 32, 162-166.

Limmathurotsakul, D., Dance, D. A., Wuthiekanun, V., Kaestli, M., Mayo, M., Warner, J., et al. (2013). Systematic review and consensus guidelines for environmental sampling of Burkholderia pseudomallei. PLoS Negl. Trop. Dis. 7:e2105. doi: 10.1371/journal.pntd.0002105

Limmathurotsakul, D., Wuthiekanun, V., Chantratita, N., Wongsuvan, G., Amornchai, P., Day, N. P. J., et al. (2010). Burkholderia pseudomallei is spatially distributed in soil in northeast Thailand. PLoS Negl. Trop. Dis. 4:e694. doi: 10.1371/journal.pntd.0000694

McDaniel, L. D., Delarosa, M., and Paul, J. H. (2006). Temperate and lytic cyanophages from the gulf of mexico. J. Mar. Biol. Assoc. 86, 517-527. doi: $10.1017 /$ S0025315406013427

McNerney, R., Wilson, S. M., Sidhu, A. M., Harley, V. S., Al Suwaidi, Z., Nye, P. M., et al. (1998). Inactivation of mycobacteriophage D29 using ferrous ammonium sulphate as a tool for the detection of viable Mycobacterium smegmatis and M-tuberculosis. Res. Microbiol. 149, 487-495. doi: 10.1016/S0923-2508(98)8 0003-X

O’Driscoll, J., Glynn, F., Cahalane, O., O'connell-Motherway, M., Fitzgerald, G. F., and Van Sinderen, D. (2004). Lactococcal plasmid pNP40 encodes a novel, temperature-sensitive restriction-modification system. Appl. Environ. Microbiol. 70, 5546-5556. doi: 10.1128/AEM.70.9.5546-5556.2004

Prentki, P., Chandler, M., and Caro, L. (1977). Replication of prophage-P1 during cell-cycle of Escherichia Coli. Mol. Gen. Genet. 152, 71-76. doi: 10.1007/BF00264942

Ronning, C. M., Losada, L., Brinkac, L., Inman, J., Ulrich, R. L., Schell, M., et al. (2010). Genetic and phenotypic diversity in Burkholderia: contributions by prophage and phage-like elements. BMC Microbiol. 10:202. doi: $10.1186 / 1471-2180-10-202$ 
Sambrook, J., Fritsch, E. F., and Maniatis, T. (1989). Molecular Cloning: A Laboratory Manual. New York, NY: Cold Spring Harbor Laboratory.

Sanders, M. E., and Klaenhammer, T. R. (1984). Phage resistance in a phage-insensitive strain of streptococcus lactis: temperature-dependent phage development and host-controlled phage replication. Appl. Environ. Microbiol. 47, 979-985.

Shan, J. Y., Patel, K. V., Hickenbotham, P. T., Nale, J. Y., Hargreaves, K. R., and Clokie, M. R. J. (2012). Prophage carriage and diversity within clinically relevan strains of clostridium difficile. Appl. Environ. Microbiol. 78, 6027-6034. doi: 10.1128/AEM.01311-12

Staley, J. T., and Konopka, A. (1985). Measurement of insitu activities of nonphotosynthetic microorganisms in aquatic and terrestrial habitats. Annu. Rev. Microbiol. 39, 321-346. doi: 10.1146/annurev.mi.39.100185.001541

Suttle, C. A. (2007). Marine viruses - Major players in the global ecosystem. Nat. Rev. Microbiol. 5, 801-812. doi: 10.1038/nrmicro1750

Suzuki, M., Matsumoto, S., Mizoguchi, M., Hirata, S., Takagi, K., Hashimoto, I., et al. (2002). Identification of (3S, 9R)- and (3S, 9S)-megastigma-6,7-dien3,5,9-triol 9-O-beta-D-glucopyranosides as damascenone progenitors in the flowers of Rosa damascena Mill. Biosci. Biotechnol. Biochem. 66, 2692-2697. doi: 10.1271/bbb.66.2692

Tamura, K., Dudley, J., Nei, M., and Kumar, S. (2007). MEGA4: molecular evolutionary genetics analysis (MEGA) software version 4.0. Mol. Biol. Evol. 24, 1596-1599. doi: 10.1093/molbev/msm092

Trung, T. T., Hetzer, A., Gohler, A., Topfstedt, E., Wuthiekanun, V., Limmathurotsakul, D., et al. (2011). Highly sensitive direct detection and quantification of Burkholderia pseudomallei bacteria in environmental soil samples by using realtime PCR. Appl. Environ. Microbiol. 77, 6486-6494. doi: 10.1128/AEM.00735-11

Utter, B., Deutsch, D. R., Schuch, R., Winer, B. Y., Verratti, K., Bishop-Lilly, K., et al. (2014). Beyond the chromosome: the prevalence of unique extra-chromosomal bacteriophages with integrated virulence genes in pathogenic staphylococcus aureus. PLoS ONE 9:e100502. doi: 10.1371/journal.pone.0100502

Wiersinga, W. J., Currie, B. J., and Peacock, S. J. (2012). Melioidosis. N. Engl. J. Med. 367, 1035-1044. doi: 10.1056/NEJMra1204699

Yordpratum, U., Tattawasart, U., Wongratanacheewin, S., and Sermswan, R. W. (2011). Novel lytic bacteriophages from soil that lyse Burkholderia pseudomallei. FEMS Microbiol. Lett. 314, 81-88. doi: 10.1111/j.1574-6968.2010.02150.x

Zhao, Y. L., Temperton, B., Thrash, J. C., Schwalbach, M. S., Vergin, K. L., Landry, Z. C., et al. (2013). Abundant SAR11 viruses in the ocean. Nature 494, 357-360. doi: $10.1038 /$ nature 11921

Conflict of Interest Statement: The authors declare that the research was conducted in the absence of any commercial or financial relationships that could be construed as a potential conflict of interest.

Received: 03 August 2014; accepted: 22 October 2014; published online: 14 November 2014.

Citation: Shan J, Korbsrisate S, Withatanung P, Adler NL, Clokie MRJ and Galyov EE (2014) Temperature dependent bacteriophages of a tropical bacterial pathogen. Front. Microbiol. 5:599. doi: 10.3389/fmicb.2014.00599

This article was submitted to Evolutionary and Genomic Microbiology, a section of the journal Frontiers in Microbiology.

Copyright (c) 2014 Shan, Korbsrisate, Withatanung, Adler, Clokie and Galyov. This is an open-access article distributed under the terms of the Creative Commons Attribution License (CC BY). The use, distribution or reproduction in other forums is permitted, provided the original author(s) or licensor are credited and that the original publication in this journal is cited, in accordance with accepted academic practice. No use, distribution or reproduction is permitted which does not comply with these terms. 